\title{
Responses to Exogenous Adenosine 3',5'-monophos- phate of Cardiac Output and Blood Flow in the Renal, Superior Mesenteric and Carotid Arteries in Anesthetized Dogs
}

\author{
Hirofumi Nozaki and Akira OkUaki \\ Department of Anesthesiology, Fukushima Medical College, \\ Fukushima
}

Nozaki, H. and Oкuакт, A. Responses to Exogenous Adenosine $3^{\prime}, 5^{\prime}$. monophosphate of Cardiac Output and Blood Flow in the Renal, Superior Mesenteric and Carotid Arteries in Anesthetized Dogs. Tohoku J. exp. Med., 1974, 112 (2), 119-128 — Changes in the cardiac output and blood flow in the renal, superior mesenteric and carotid arteries in anesthetized dogs were observed, using the noncannulating electromagnetic flow meter. Cyclic AMP, $10 \mathrm{mg}$ per kilogram of body weight, was given intravenously and the following results were obtained: 1) Cyclic AMP slightly decreased the heart rate, and increased the stroke volume and cardiac output. 2) Both systemic blood pressure and central venous pressure were decreased. 3) The renal blood flow decreased for the first few minutes, and increased after 10 minutes, but the superior mesenteric and carotid blood flows increased. 4) Distribution ratio in the renal artery decreased for a short time, while those in the superior mesenteric and carotid arteries increased. 5) Cardiac output was depressed by propranolol $(0.5 \mathrm{mg} / \mathrm{kg})$, but not enhanced by aminophylline $(5 \mathrm{mg} / \mathrm{kg})$. — adenosine $3^{\prime}, 5^{\prime}$-monophosphate; blood circulation

Although a considerable amount of report has been published on inotropic response to adenosine $3^{\prime}, 5^{\prime}$-monophosphate (cyclic AMP), in most of them positive inotropic response was not found because this substance cannot enter the intracellular space. Concerning chronotropic response, negative effect was observed like other adenosine nucleotides. However, Levine and co-workers reported that a relatively large amount of cyclic AMP given intravenously increased the heart rate and cardiac output in both dogs (Levine and Vogel 1965, 1966) and man (Levine et al. 1968). In this study, we examined cardiohemodynamic response to cyclic AMP in dogs, measuring simultaneously the cardiac output and peripheral blood flow in the renal, superior mesenteric and carotid arteries. From these

Received for publication, May 14, 1973.

Following abbreviations were used in the present paper: C.V.P., central venous pressure; S.B.P., systemic blood pressure; C.O., cardiac output; R.A.B.F., renal artery blood flow; S.M.A.B.F., superior mesenteric artery blood flow; C.A.B.F., carotid artery blood flow; H.R., heart rate; M.S.B.P., mean systemic blood pressure; S.V., stroke volume; T.P.V.R., total peripheral vascular resistance; R.A.V.R., renal artery vascular resistance; S.M.A.V.R., superior mesenteric artery vascular resistance; C.A.V.R., carotid artery vascular resistance; R.D.Ra., renal distribution ratio; S.M.D.Ra., superior mesenteric distribution ratio; C.D.Ra., carotid distribution ratio. 
results, distribution ratios of cardiac output to each peripheral vascular bed were calculated in order to suggest the effective site of this compound.

\section{Methods}

Seventeen adult mongrel dogs of both sexes, weighing 12 to 22 kilograms, were anesthetized with cyclohexylamine $(12 \mathrm{mg} / \mathrm{kg}$ i.m.) and sodium pentobarbital $(30 \mathrm{mg} / \mathrm{kg}$ i.m.). Artificial respiration, 20 per min and $15 \mathrm{ml} / \mathrm{kg}$ of tidal volume, was performed through intubation into the trachea by Aika Respirater (R-60).

The left chest was opened in the 4th intercostal space and the ascending aorta was exposed to place the non-cannulating flow meter probe around it. The left renal and superior mesenteric arteries were dissected retroperitoneally. Non-cannulating flow meter probes of adequate size for each artery were placed around the left renal, superior mesenteric and left carotid, arteries. An electromagnetic flow meter (Nihon Kohden MF46) was used for measuring the blood flow. Stroke volume was calculated from the flow curve obtained at the ascending aorta. Mean systemic blood pressure and central venous pressure were measured by electric transducer (Nihon Kohden PPU-05 and LPU-05) at the right femoral artery and the intrathoracic vein. ECG (lead II) was used for observing changes in heart rate. Vascular resistance for each vascular bed was calculated from the mean systemic blood pressure and cardiac output, or rates of blood flow in the renal, superior mesenteric and carotid arteries. Distribution ratio of each peripheral artery was expressed in per cent of the mean rate of blood flow to the cardiac output.

Drugs used were $3^{\prime}, 5^{\prime}$-cyclic AMP (supplied by Seishin Seiyaku), propranolol (Sumitomo Kagaku) and aminophylline (Eizai). Cyclic AMP was dissolved in $5 \mathrm{ml}$ of $0.9 \%$ physiologic saline. Every drug solution was administered intravenously from the left bacilic vein. Drug effect was observed for one hour.

\section{ResUlts}

\section{Effects of cyclic $A M P$ on the circulation}

After a single injection of cyclic AMP at the dosage of $10 \mathrm{mg}$ per kilogram to anesthetized dogs, the cardiac output, superior mesenteric and carotid artery blood flow increased, but the renal artery blood flow decreased. Both the central venous pressure and systemic blood pressure fell slightly (Fig. 1). The heart rate

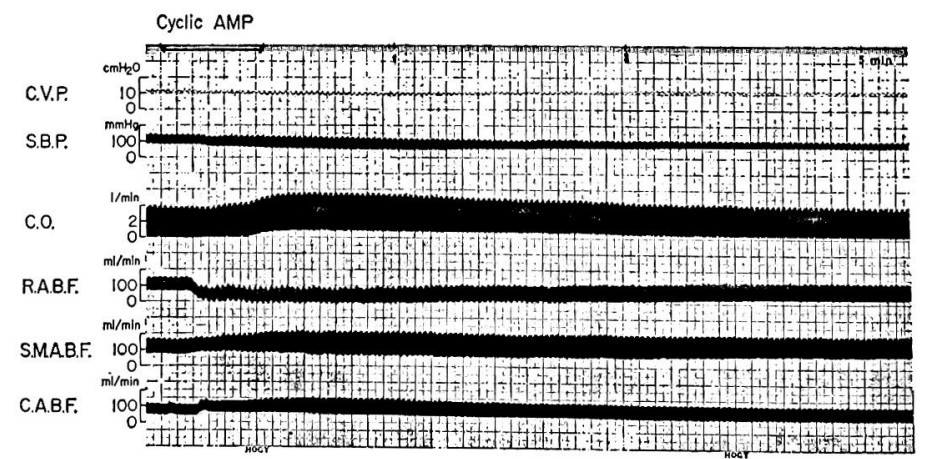

Fig. 1. Initial cardiohemodynamic response to cyclic AMP, $10 \mathrm{mg} / \mathrm{kg}$, i.v., (Dog's weight was $12 \mathrm{~kg}$ ). Abbreviations are given in foot note. 


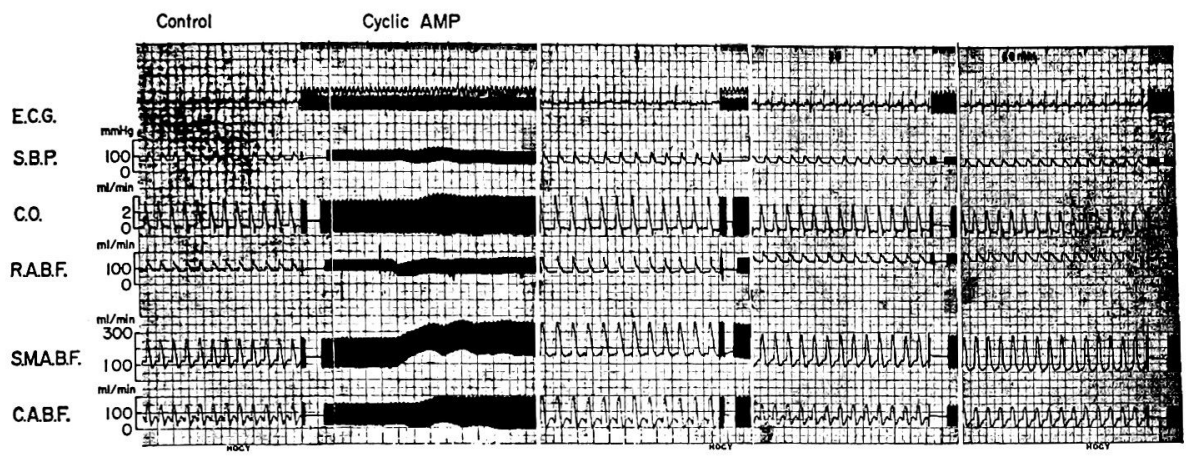

Fig. 2. Circulatory responses to cyclic AMP, $10 \mathrm{mg} / \mathrm{kg}$, i.v. for sixty minutes. (Dog's weight was $16 \mathrm{~kg}$ ). Abbreviations are given in foot note.

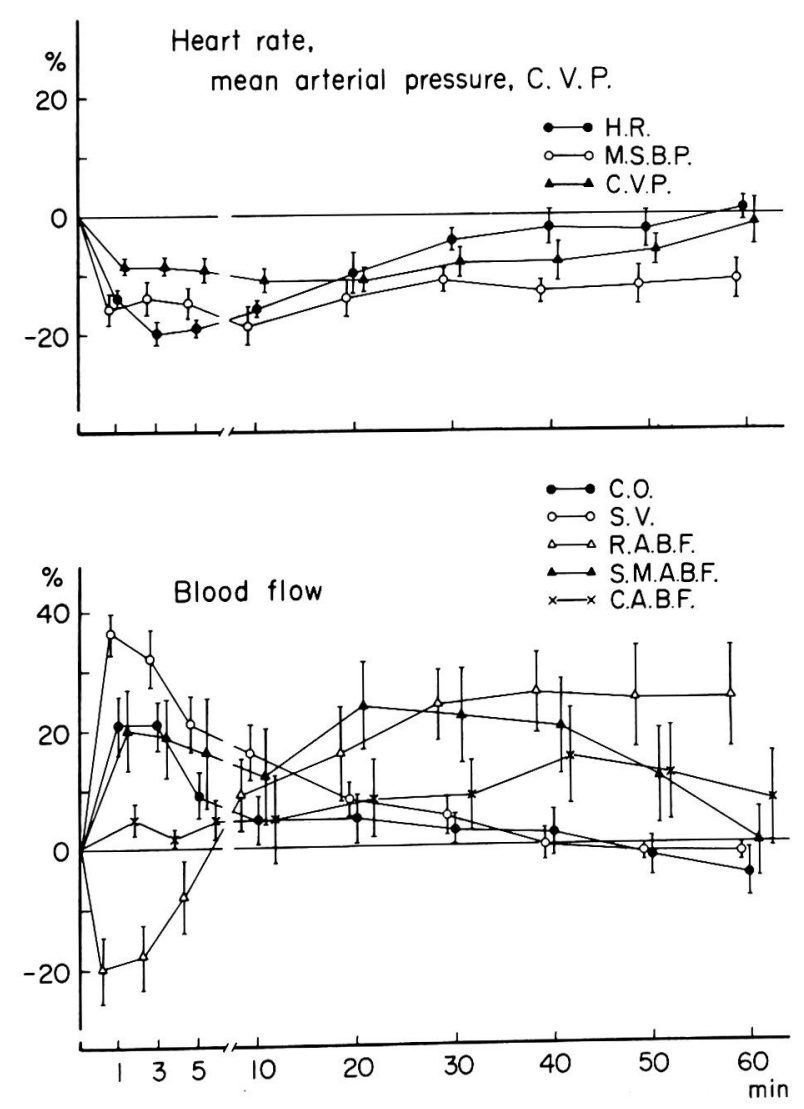

Fig. 3. Changes in circulatory parameters induced by cyclic AMP, $10 \mathrm{mg} / \mathrm{kg}$, i.v. Abbreviations are given in foot note. 
decreased in ECG, but the stroke volume, cardiac output and superior mesenteric artery blood flow increased remarkably. The renal artery blood flow decreased for a short time but recovered 3 minutes after the injection (Fig. 2). The results of changes in each circulatory parameter are summarized in Figs. 3 and 4 . The heart rate decreased by $19 \%$ at 3 minutes and returned to the control level at 60 minutes. The mean systemic blood pressure decreased by $18 \%$ at 10 minutes and maintained this level for 60 minutes. The central venous pressure decreased slightly. With regard to the blood flow, the cardiac output increased by $21 \%$ at 3 minutes, and recovered to the control value within 30 minutes. The stroke volume increased by $37 \%$ at one minute and returned to the control level at 30 minutes. The renal artery blood flow decreased by $19 \%$ at one minute but increased by $9 \%$ at 10 minutes, showing a diphasic phenomenon. The superior mesenteric blood flow increased by $21 \%$ at one minute and returned to the control value 60 minutes later. The carotid blood flow increased by $7 \%$ at 10 minutes and maintained this level for one hour observation time.

The total peripheral vascular resistance and the superior mesenteric and

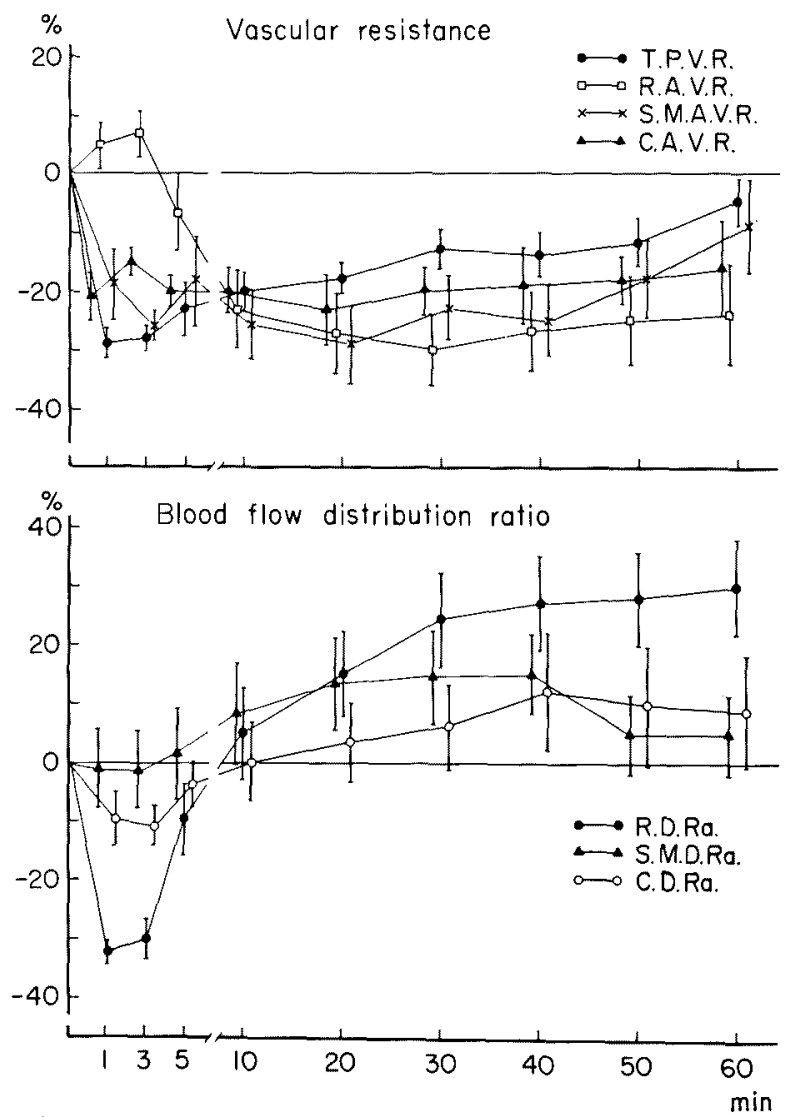

Fig. 4. Changes in circulatory parameters induced by cyclic AMP, $10 \mathrm{mg} / \mathrm{kg}$, i.v. For abbreviations see foot note. 


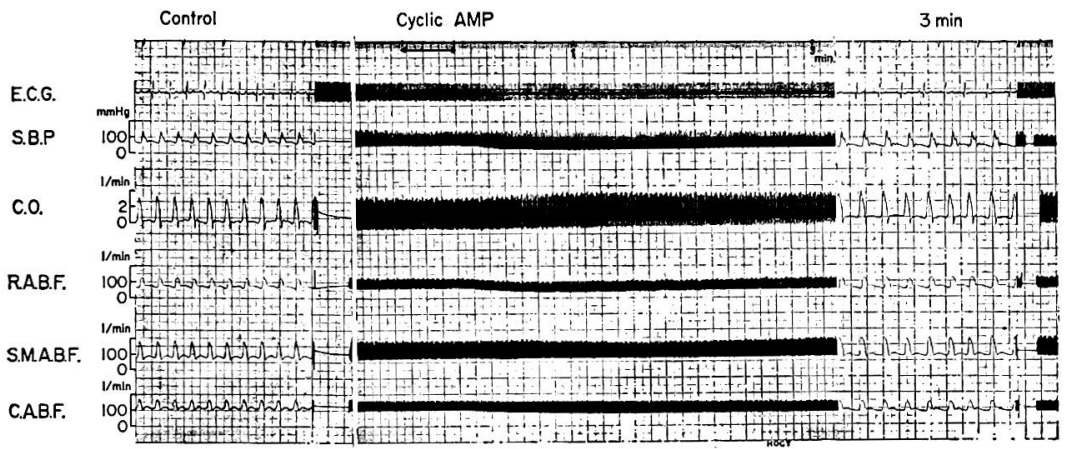

Fig. 5. Circulatory responses to cyclic AMP, $10 \mathrm{mg} / \mathrm{kg}$, i.v. 5 minutes after propranolol, $0.5 \mathrm{mg} / \mathrm{kg}$, i.v. (Dog's weight was $14 \mathrm{~kg}$ ). Abbreviations are the same with those in Fig. 2.

carotid vascular resistances decreased, while the renal one increased slightly for the first few minutes and began to decrease at about 5 minutes.

Changes in distribution ratio to each peripheral circulation were as follows: Distribution to the renal circulation decreased by $32 \%$ at one minute but began to increase at 10 minutes and increased by $17 \%$ at 20 minutes, and those to the superior mesenteric and the carotid arteries decreased slightly at first but increased at 20 minutes.

\section{Pretreatment with propranolol}

Fig. 5 shows one of the typical results on the effect of cyclic AMP after propranolol treatment. Cyclic AMP $(10 \mathrm{mg} / \mathrm{kg})$ was injected 5 minutes after propranolol treatment $(0.5 \mathrm{mg} / \mathrm{kg})$. The heart rate decreased and systemic blood pressure fell slightly. The cardiac output still increased after propranolol treatment though less significantly than before treatment. No change was observed in the blood flow of the renal, superior mesenteric and carotid arteries. The results of changes in each circulatory parameter after propranolol treatment are summarized in Figs. 6 and 7. The heart rate decreased slightly for a short time, but returned to the control level at 40 minutes. The mean systemic pressure and central venous pressure decreased to the same degree as observed before treatment. The changes in cardiac output, stroke volume and blood flow in the renal and superior mesenteric arteries were less than before treatment. The carotid blood flow decreased slightly. All vascular resistances decreased to the same degree as observed before treatment. Distribution to the renal, superior mesenteric and carotid arteries decreased.

\section{Pretreatment with aminophylline}

Fig. 8 shows one of the typical results in cardiac hemodynamic change induced 


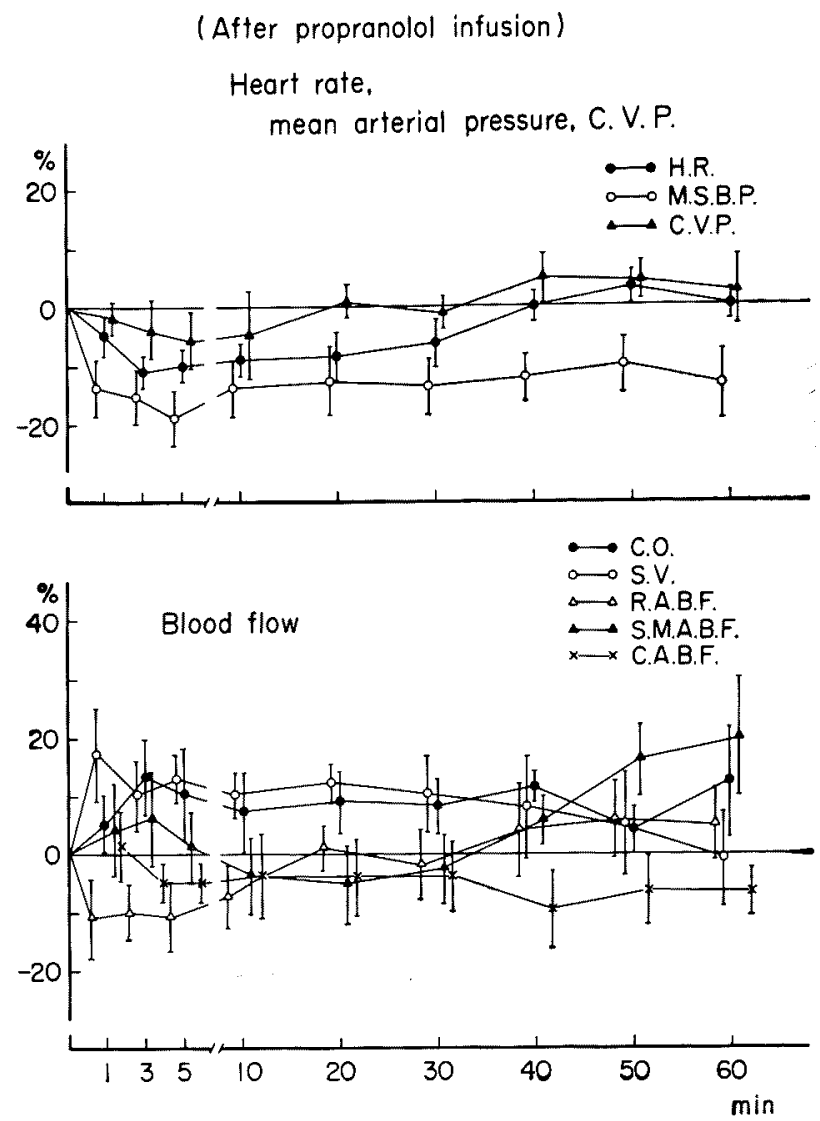

Fig. 6. Changes in circulatory parameters induced by cyclic AMP, $10 \mathrm{mg} / \mathrm{kg}$, i.v. after propranolol, $0.5 \mathrm{mg} / \mathrm{kg}$. Abbreviations are the same with those in Fig. 3.

by the injection of aminophylline $(5 \mathrm{mg} / \mathrm{kg}$ ) and by the cyclic AMP $(10 \mathrm{mg} / \mathrm{kg})$ injection 5 minutes after aminophylline treatment. Aminophylline elevated slightly the mean systemic pressure and increased the cardiac output and blood flows in the superior mesenteric and carotid arteries, but slightly decreased the renal blood flow. When cyclic AMP was given 5 minutes after aminophylline treatment, the mean systemic blood pressure decreased while the cardiac output increased slightly. The renal blood flow still decreased slightly but the blood flow of the superior mesenteric and carotid arteries scarcely changed. The results of changes in circulatory parameter after aminophylline treatment are summarized in Figs. 9 and 10. The heart rate, mean arterial pressure and central venous pressure decreased to the same degree as observed before aminophylline treatment. Thus, the stroke volume increased, and cardiac output also increased a little. Blood flow in both the renal and the superior mesenteric arteries decreased slightly, but that of the carotid artery increased. The total, renal and superior mesenteric vascular resistances decreased less significantly than before aminophylline, but the 
(After propranolol infusion)
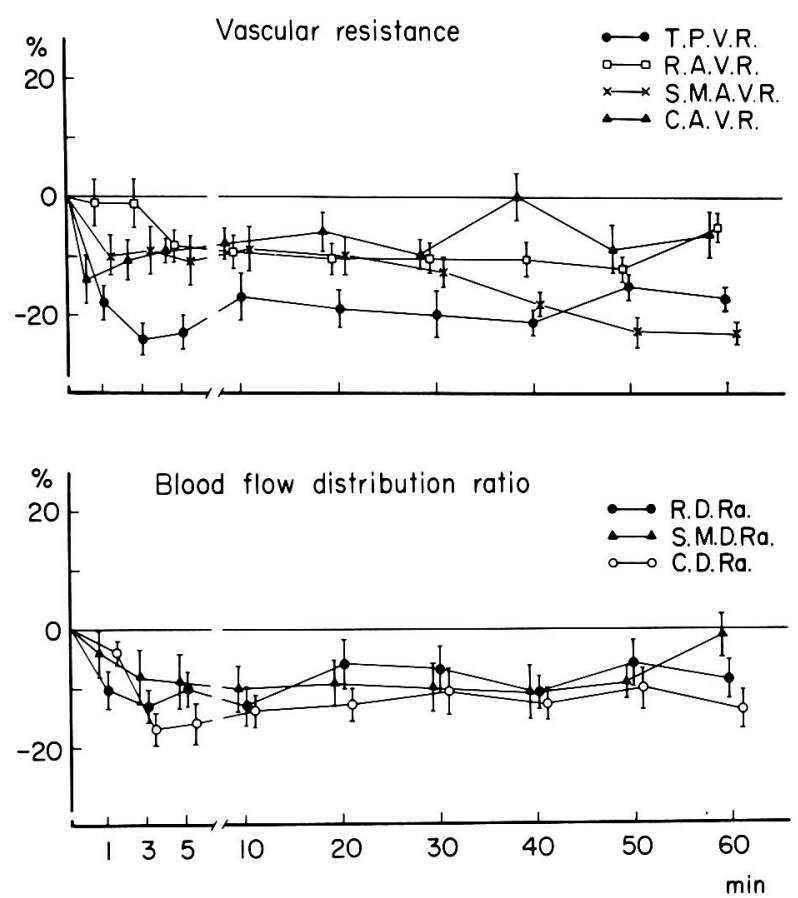

Fig. 7. Changes in circulatory parameters induced by cyclic AMP, $10 \mathrm{mg} / \mathrm{kg}$, i.v. after propranolol, $0.5 \mathrm{mg} / \mathrm{kg}$. Abbreviations are the same with those in Fig. 4.

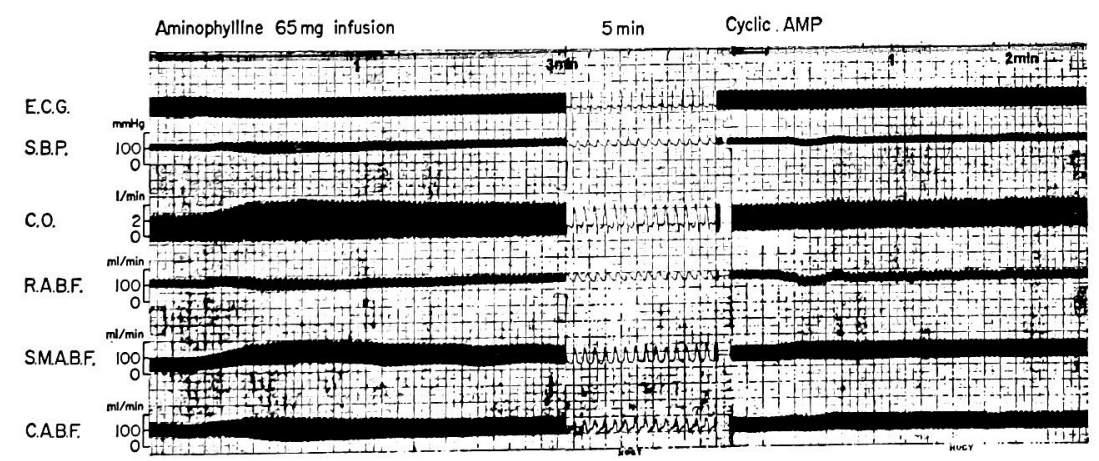

Fig. 8. Circulatory responses to cyclic AMP, $10 \mathrm{mg} / \mathrm{kg}$, i.v. after aminophylline, $5 \mathrm{mg} / \mathrm{kg}$, i.v. (Dog's weight was $13 \mathrm{~kg}$ ). Abbreviations are the same with those in Fig. 2.

carotid vascular resistance decreased significantly. Distribution to the carotid artery increased but those to the renal and superior mesenteric arteries changed little. 


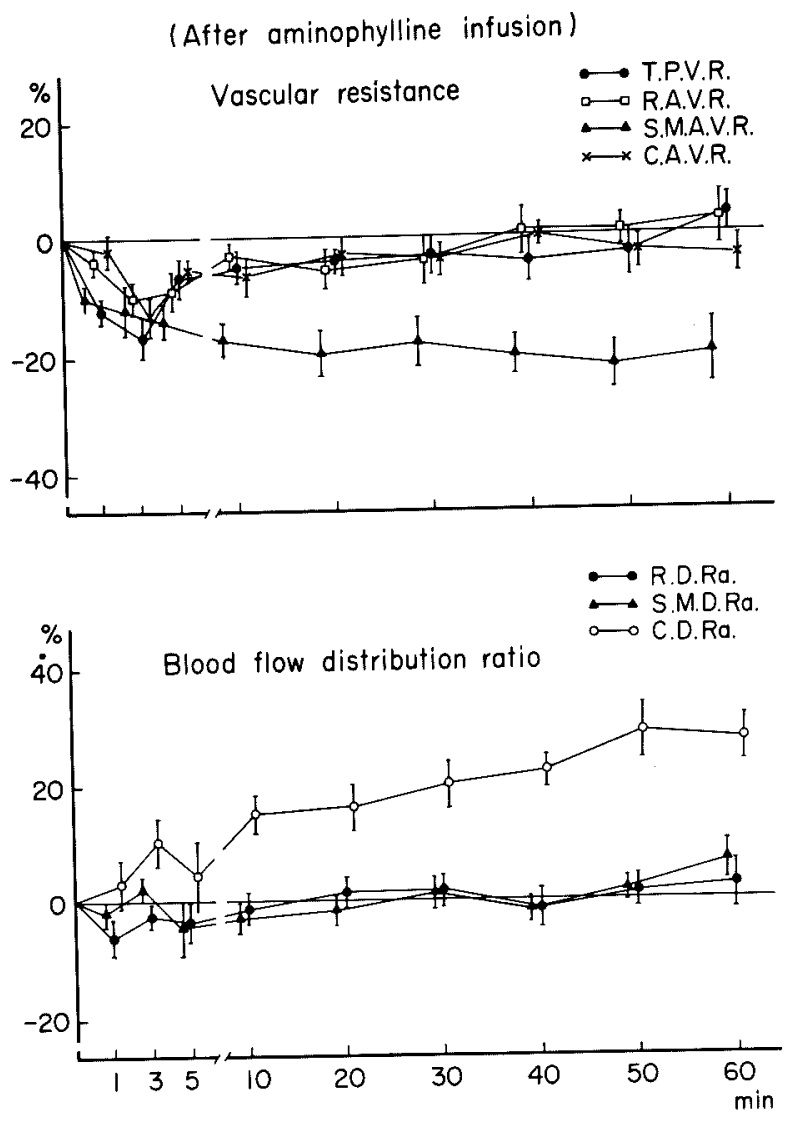

Fig. 9. Changes in circulatory parameters induced by cyclic AMP, $10 \mathrm{mg} / \mathrm{kg}$, i.v. after aminophylline, $5 \mathrm{mg} / \mathrm{kg}$, i.v. Abbreviations are the same with those in Fig. 3 .

\section{Discussion}

It is well documented that catecholamine activates adenyl cyclase, resulting from increase of cyclic AMP concentration in the myocardium, and that the increase of cyclic AMP produces the positive inotropic action (Rall and West 1963; Robison et al. 1965, 1967; Namm and Mayer 1968). On the other hand, exogenous cyclic AMP has no $\beta$-adrenergic stimulation (Henion et al. 1969; McNeill et al. 1969) because labeled cyclic AMP cannot pass across the cell membrane (Robison et al. 1965). Levine and co-workers $(1965,1966,1968)$, however, reported that the heart rate and cardiac output increased by injection of cyclic AMP in dogs and man. In these experiments, cyclic AMP decreased the heart rate, while the stroke volume and cardiac output were increased. The increase of cardiac output was depressed by propranolol treatment and it was not enhanced but rather depressed by aminophylline treatment. At the same time, cyclic AMP increased flow rates of the superior mesenteric and the carotid arteries, but decreased initially that of the renal artery. 
(After aminophylline infusion)

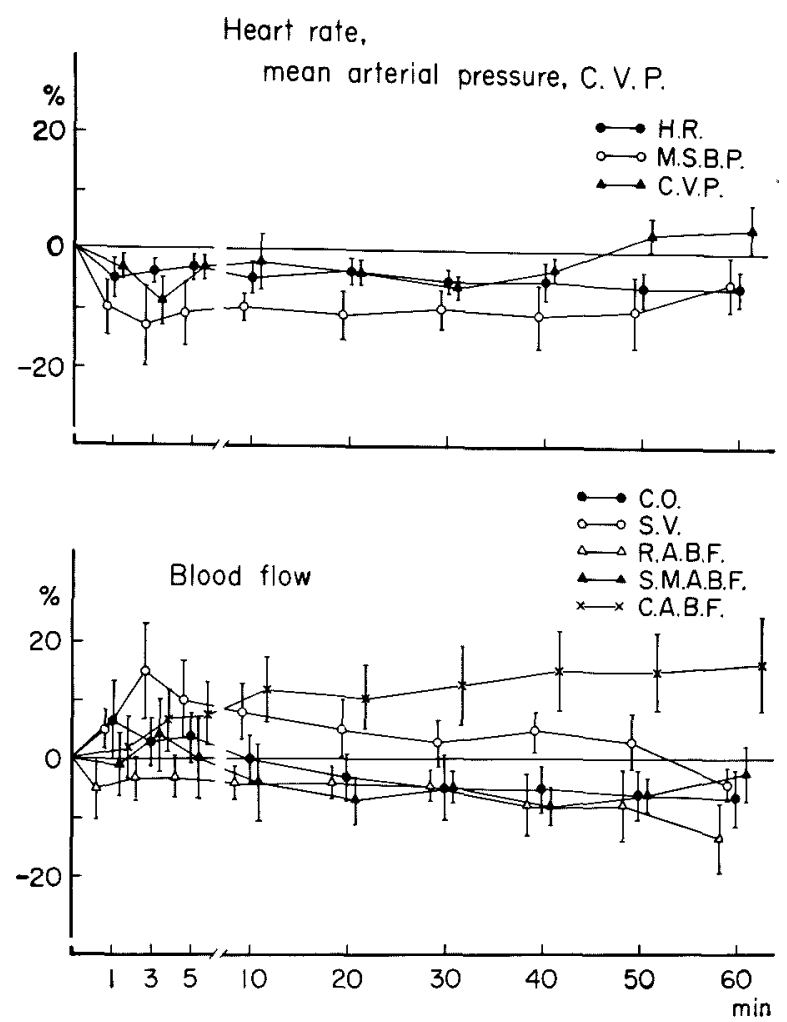

Fig. 10. Changes in circulatory parameters induced by cyclic AMP, $10 \mathrm{mg} / \mathrm{kg}$, i.v. after aminophylline, $5 \mathrm{mg} / \mathrm{kg}$, i.v. Abbreviations are the same with those in Fig. 4.

Distribution ratio in the superior mesenteric and the carotid arteries increased, while it decreased in the renal artery for a short time which recovered at 10 minutes afterward.

From these results, it was revealed that cyclic AMP increased the blood flow in both the intestine and the brain, while it decreased that in the kidney for a short time. As for the mechanism of increasing cardiac output of cyclic AMP, Levine and co-workers $(1966,1968)$ suggested that cyclic AMP dilates peripheral vessel and increases a direct heart action. The increase in stroke volume and cardiac output, which were depressed by propranolol, suggests that cyclic AMP increases heart muscle contraction through induction of adrenergic mechanism. It is supported by no enhancement of aminophylline on the positive inotropic action of cyclic AMP. Thus it seems that the myocardial contraction was increased by indirect action. On the other hand, cyclic AMP decreased not only in the total but also in the superior mesenteric and the carotid vascular resistances. Although Hashimoto and Kumakura (1965) reported that the renal artery vascular 
resistance was increased by cyclic AMP, the vascular resistance was increased only for a few minutes, and it decreased immediately in these experiments.

\section{Acknowledgment}

We wish to acknowledge Prof. K. Hashimoto, the Department of Pharmacology, Tohoku University School of Medicine, for his kind advice and revision of the manuscript.

\section{References}

1) Hashimoto, K. \& Kumakura, S. (1965) The pharmacological features of the coronary, renal, mesenteric and femoral arteries. Jap. J. Physiol., 15, 540-551.

2) Henion, W.F., Sutherland, E.W. \& Posternak, T. (1969) Effects of derivatives of adenosine $3^{\prime}, 5^{\prime}$-phosphate on liver slices and intact animals. Biochim. biophys. Acta (Amst.), 148, 106-113.

3) Levine, R.A., Dixon, L.M. \& Franklin, B.B. (1968) Effects of exogenous adenosine $3^{\prime}, 5^{\prime}$-monophosphate in man. Clin. Pharmacol. Ther., 9, 168-179.

4) Levine, R.A. \& Vogel, J.A. (1965) Cardiovascular and metabolic effects of adenosine 3', 5'-monophosphate in vivo. Nature, 207, 987-988.

5) Levine, R.A. \& Vogel, J.A. (1966) Cardiovascular and metabolic effects of cyclic adenosine $3^{\prime}, 5^{\prime}$-monophosphate in unanesthetized dogs. J. Pharmacol. exp. Ther., 151, 262-272.

6) MeNeill, J.H., Nassar, M. \& Brody, T.M. (1969) The effect of theophylline on amineinduced cardiac phosphorylase activation and cardiac contractility. J. Pharmacol. exp. Ther., 165, 234-241.

7) Namm, D.H. \& Mayer, S.E. (1968) Effects of epinephrine on cardiac cyclic $3^{\prime}, 5^{\prime}$-AMP, phosphorylase kinase and phosphorylase. Molec. Pharmacol., 4, 61-69.

8) Rall, T.W. \& West, T.C. (1963) The potentiation of cardiac inotropic responses to norepinephrine by theophylline. J. Pharmacol. exp. Ther., 139, 269-274.

9) Robison, G.A., Butcher, R.W., Oye, I. Morgan, H.E. \& Sutherland, E.W. (1965) The effect of epinephrine on adenosine $3^{\prime}, 5^{\prime}$-phosphate levels in the isolated perfused rat heart. Molec. Pharmacol., 1, 168-177.

10) Robison, G.A., Butcher, R.W. \& Sutherland, E.W. (1967) Adenyl cyclase as an adrenergic receptor. Ann. N.Y. Acad. Sci., 139, 703-723. 